\title{
THE IMPACT OF FOREIGN DIRECT INVESTMENTS ON TURKISH ECONOMY
}

\author{
DOI: 10.17261/Pressacademia.2020.1342 \\ PAP- V.12-2020(6)-p.27-30
}

\section{Fatih Kilic ${ }^{1}$, Dilek Teker ${ }^{2}$}

${ }^{1}$ Işık University, Institute of Social Sciences, Istanbul, Turkey fatih kilic43@hotmail.com ORCID: 0000-0003-4373-8796

${ }^{2}$ Işık University, Faculty of Economics and Administrative Sciences, Department of Management, Istanbul, Turkey. dilek.teker@isikun.edu.tr, ORCID: 0000-0002-3893-4015

\section{To cite this document}

Kilic, F., Teker, D., (2020). The impact of foreign direct investments on Turkish economy. PressAcademia Procedia (PAP), V.12, p.27-30. Permanent link to this document: http://doi.org/10.17261/Pressacademia.2020.1342

Copyright: Published by PressAcademia and limited licensed re-use rights only.

\section{ABSTRACT}

Purpose- In this study, inflation rate, unemployment rate and the index of industrial production, foreign direct investment coming to Turkey are examined on whether this is effective.

Methodology :The data analyzed are FDI, unemployment rate, inflation rate and industrial production index with the highest share in GDP. Monthly data covering the period between January 2005 and May 2020 were used. The data in the tests have been obtained from the CBRT EDDS, TURKSTAT and the World Bank.

Findings- The series are found out to be stationary at level. According to the cointegration test result, cointegration could found between all our data. Impulse response graphs indicate that all variables respond in a reducing way to reducing shocks occurred in each indicator. Shocks have lost their effect on average in 3 days.

Conclusion- In the Turkish economy, it is seen that there is a close relationship between foreign direct investment and economic growth indicators inflation, unemployment, Industrial Production Index in the long term.

Keywords: Foreign direct investment, Turkey's economy, inflation, unemployment, industrial-production index, JEL Codes: A10, E20, E24

\section{DOĞRUDAN YABANCI YATIRIMLARIN TÜRKIYE EKONOMISI ÜZERINDEKI ETKISININ INCELENMESi}

\section{ÖZET}

Amaç- Bu çalışmada enflasyon oranı, işsizlik oranı ve sanayi üretim endeksinin, Türkiye’ye gelen doğrudan yabancı sermaye yatırımları üzerinde etkili olup olmadı̆̆ı incelenmektedir.

Yöntem- Analize tabi tutulan datalar DYY, işsizlik oranı, enflasyon oranı ve GSYiH içindeki en yüksek paya sahip olan sanayi üretim endeksidir. Ocak 2005 - Mayıs 2020 arasındaki dönemleri kapsayan aylık veriler kullanılmıştır. Testlerdeki datalar TCMB EVDS, TÜik ve Dünya Bankası'ndan alınmıştır.

Bulgular- Serileimiz düzey değerde durağan çıkmıştır.Eş bütünleşme test sonucuna göre ,tüm değerlerimizin eş bütünleşik olduğu gözlemlenmiştir.Etki tepki grafiklerine göre tüm değişkenler, her göstergede meydana gelen şokları azaltmak için indirgeyici bir şekilde yanıt vermektedir. Şoklar etkisini ortalama 3 ayda kaybetmiştir.

Sonuç- Türkiye ekonomisinde doğrudan yabancı sermaye yatırımları ile ekonomik büyüme göstergeleri enflasyon, işsizlik, sanayi üretim endeksi arasında uzun dönemde sıkı ilişki içerisinde olduğu görülmektedir.

Anahtar Kelimeler: Doğrudan yabancı yatırımlar,Türkiye ekonomisi, enflasyon, işsizlik, sanayi-üretim endeksi. JEL Kodları: A10, E20, E24 


\section{Gíriş}

Yeni yatırım araçlarının yaratılması, bunların etkinliğini artıran haberleşme ve bilgi işlem teknolojilerinin hızla gelişerek rekabet rüzgârlarının global düzeye ulaşması ve uluslararası sermaye hareketlerinin serbestleşmeye başlaması küreselleşme kavramını ortaya çıkarmıştır. Gelişmiş ve gelişmekte olan ülkeler açısından bir fırsat niteliği kazanan bu sermaye hareketliliği o günlerden günümüze kadar dünya piyasalarında faaliyet alanı bulmaya devam etmiştir (Canbay, 2018). Başlangıçta mal ve hizmetlerin serbest dolaşımı yönünde atılan adımlar, 1980'lere gelindiğinde tüm dünyada baş gösteren küreselleşme akımları ile birlikte finansal sermayenin de ülkeler arasında çok hızlı bir şekilde hareket etmesi sonucunu doğurmuştur. 1980 sonrası dünyada hız kazanan küreselleşmeyle birlikte tüm ülkeler bu yapıya uyum sağlamak zorunda bırakıldı. Türkiye kötü ekonomik gidişatı durdurmak, ekonomide istikrarlı bir büyümeyi sağlamak, enflasyonu kontrol altına almak gibi dünya piyasaları ile bütünleşme amacı taşıyan "ekonomik istikrar programı" olarak da adlandırılan 24 Ocak 1980 Kararları ile serbest piyasa ekonomisine geçişte büyük adım atmıştır. 1980 yılından sonra Türkiye'ye gelen DYY' de ciddi oranda artışlar gerçekleşmiştir. Bu artışın altındaki temel sebep 24 Ocak 1980 Ekonomik İstikrar Kararlarıdır. Bu kararlar ile birlikte Türkiye tamamen dışa açık bir dış politika izlemeye başlamış, ülkede politik ve ekonomik istikrar yeniden kurulmuş, yabancı sermayenin dolaşımı tamamen serbest bırakılmış ve yabancı sermayeye, uygulanan politikalarla güven verilmiştir. Dışa açılma sürecine girmenin etkisiyle ülkeye gelen DYY zaman içinde artış sergilemiş ve bu da cari açığın azalarak 1988 ve 1989 yılında cari fazla vermesine olumlu katkı yapmıştır. 1980 yılında toplam ihracat 3.6 milyar usd iken gelen yatırımların etkisiyle 1989 yılında 11.6 milyar usd seviyelerine çıkmış ve yaklaşık 3 kat artmıştır. Ülke ekonomisine olumlu katkıları olan yatırımların enflasyon ve işsizlik üzerinde de etkisi de açıkça görülmektedir. 1980 yılında \%93 enflasyon ve \%94,30 olan işsizlik 1987 yılında yaklaşık 6,5 kat artan DYY nin etkisiyle \%38 seviyelerine gerilemiştir. Bir diğer dikkat edilmesi gereken nokta ise GSYiH tutarındaki değişikliktir. 1980 yılında 94.7 milyar usd olan GSYiH, 1989 yılında gelen yatırımlarla birlikte 147.5 milyar usd seviyelerine çıkmıştır. 1980 istikrar programı, içe yönelik ithal ikameci kalkınma stratejisinden, dışa yönelik kalkınma stratejisine doğru önemli bir gelişme sağlarken, ticaret ve sermaye hareketleri liberasyonuna geçişi de mümkün kılmıştır

\section{LITERATÜR INCELEMESI}

Alagöz vd. (2008), 1992-2007 yılları arasında çeyreklik veriler ile DYY ile GSYiH arasındaki ilişkiyi incelemişlerdir. Veriler TCMB EVDS' den alınmıştır. DYY verileri yalın halde durağan olmasına rağmen GSYiH verileri ise birinci dereceden durağan çıkmıştır. Değişkenlerin durağanlığının test edilmesinden sonra, DYY ile ekonomik büyüme (GSYIH) arasında bir nedenselliğin olup olmadığı çift yönlü analiz edilmiştir. Buna göre \%1, \%5 ve \%10 anlamlılık düzeylerinde iki taraflı olarak nedensellik ilişkisi mevcut değildir.Mucuk vd. (2009), DYY ile ekonomik büyüme arasındaki nedensel bağıntıyı incelemişlerdir. Eş bütünleşme testi sonucunda DYY ile ekonomik büyüme değişkenlerinin uzun dönemde birlikte hareket ettikleri sonucuna ulaşılmıştır. Etki-tepki fonksiyonları ekonomik büyümenin DYY' ye ve DYY'nin de ekonomik büyümeye olumlu katkıda bulunduğunu göstermektedir. Varyans ayrıştırma ile ekonomik büyümenin doğrudan yabancı yatırımlar üzerindeki etkisinin daha zayıf olduğu anlaşılmaktadır. Yılmazer (2010), GSYiH, DYY ihracat ve ithalat değerleri arasındaki ilişkiyi test etmiştir. Çalışmada sonucunda DYY ile ekonomik büyüme arasında güçlü bir nedensellik ilişkinin olmadığı ortaya çıkmıştır. Aslan vd. (2014), Türkiye ekonomisi için sermaye akımları ile ekonomik büyüme arasındaki ilişkiyi analiz etmişlerdir. Sermaye akımlarının GSYiH üzerinde etkisi olduğu sonucuna ulaşmışlardır.Acar (2016), 2001-2015 yılları arasında Türkiye'de yabancı sermaye yatırımları ile ekonomik büyüme arasındaki ilişkiyi araştırmıştır. Test sonuçlarında ekonomik büyüme ile doğrudan yabancı sermaye yatırımları arasında herhangi bir ilişki bulunamamıştır.Koyuncu (2017), Türkiye'de doğrudan yabancı yatırımlar ile ekonomik büyüme ve istihdam arasındaki ilişkiyi incelemiştir. Eş bütünleşme testinde $\% 5$ anlamlılık düzeyinde doğrudan yabancı yatırımlar, ekonomik büyüme ve istihdam serileri arasında uzun dönemli bir ilişkinin varlığı tespit edilmiştir. Karaçor vd. (2017), Türkiye'deki DYY ile ekonomik büyüme arasındaki ilişkiyi ortaya koyma amacıyla incelemelerde bulunmuşlardır. Johansen Koentegrasyon test sonuçlarına göre uzun dönemli bir ilişkiye rastlanmıştır. Sonrasında yapılan Granger nedensellik testine göre DYY ile ekonomik büyüme arasında bir ilişki bulunamamıştır. Ağır vd. (2019), Türkiye'ye gelen doğrudan yabancı yatırımların ekonomik büyüme üzerine etkisini zaman serileri ekonometrisiyle incelemişlerdir. Değişkenler arasında eş bütünleşme ve nedensellik ilişkisi bulunamamıştır. Canbay vd. (2020), Türkiye'de DYY'nin işsizlik oranına etkisini tespit etmek üzere incelemeler yapmışlardır. Yapılan testler sonucunda eş bütünleşme ilişkisinin olduğu tespit edilmiştir.

\section{VERI VE YÖNTEM}

İstatistiki testlerde kullanılan datalarımız doğrudan yabancı yatıımlar, enflasyon, işsizlik ve GSYiH içindeki en büyük paya sahip olan ve GSYiH açıklanmadan yorum yapabilmemizi sağlayan sanayi üretimi endeksidir. Testlerde kullanılan datalardan doğrudan yabancı yatııımları TCMB EVDS ve Dünya Bankası'ndan; işsizlik, enflasyon ve sanayi üretimi endeksi ise TÜiK'den alınmıştır. Tüm datalarımız aylık frekansta olup Ocak 2005 - Mayıs 2020 arasındaki dönemleri kapsamaktadır. İsssizlik, enflasyon ve sanayi üretimi endeksi yüzdesel olarak değişim şeklinde açıklanırken, DYY rakamsal cinsten açıklanmaktadır. Durum böyle olunca tüm datalarda tek düzeliği sağlamak amacıyla bir önceki aya göre değişim alınarak yüzdesel hale getirilmiştir. Daha sonrasında değişkenlerin mutlak değerleri alınmış ve logaritmik değerleriyle testlere uygun hale getirilmiştir. Serilerin durağanlığının test edilmesi amacıyla ADF birim kök testi kullanılmışır. ADF test istatistik sonucunun mutlak değerinin Mac-Kinnon mutlak kritik değerlerinden büyük olması ve olasılık değerinin 0,05 den küçük olması sonucu tüm değişkenlerimiz düzey değerde durağandır.

Tablo 1: Birim Kök Test Sonuçları

\begin{tabular}{|c|c|c|c|c|c|}
\hline Değişken & ADF Test İstatistiği & Mac-Kinno & Kritik Değe & & Olasılık \\
\hline & & $1 \%$ & $5 \%$ & $10 \%$ & \\
\hline FDI & $-11,92087$ & $-4,008706$ & $-3,434433$ & $-3,141157$ & 0,0000 \\
\hline
\end{tabular}




\begin{tabular}{|l|c|c|c|c|c|}
\hline Sanayi Üretimi & $-15,13649$ & $-4,008706$ & $-3,434433$ & $-3,141157$ & 0,0000 \\
\hline İşsizlik & $-13,50835$ & $-4,008706$ & $-3,434433$ & $-3,141157$ & 0,0000 \\
\hline Enflasyon & $-11,57522$ & $-4,008706$ & $-3,434433$ & $-3,141157$ & 0,0000 \\
\hline
\end{tabular}

Seçilen bütün değişkenleri birlikte ele alan ve bir sistem bütünlüğü içinde inceleyen VAR modeli için, tahminlerin doğru biçimde yapılabilmesi açısından öncelikle optimal gecikme uzunluğunun belirlenmesini gerekmektedir. Gecikme uzunluklarının belirlenmesinde en yaygın yöntemler şunlardır; Olabilirlik Oranı Testi (Likelihood Ratio Test: LR), Akaike Bilgi Kriteri (Akaike Information Criterion: AIC), Hannan-Quinn Bilgi Kriteri (HQ), Son Öngörü Hatası (FPE), Schwarz Bilgi Kriteri (Schwarz Information Criterion). LR Test İstatistiği, Son Öngörü Hatası, Akaike Bilgi kriteri, Hannan-Quinn Bilgi kriteri ve Schwarz Bilgi Kriterine göre uygun gecikme uzunluğu 1 olarak gözükmektedir. Bu kriterleri minimum yapan gecikme uzunluğu, optimal olarak kabul edilmektedir.

Durağan oldukları tespit edilen değişkenler arasında uzun dönemde bir ilişkinin olup olmadığını anlayabilmek için Johansen Eş bütünleşme testi yapılmıştır. Bu test, Trace (İz) İstatistiği ve Max-Eigenvalue (Maksimum Özdeğer) istatistikleri aracılığıla yapılmıştır. 4 değişkene göre yapılan Trace (İz) İstatistiği ve Max-Eigenvalue (Maksimum Özdeğer) \%5 anlamlılık düzeyinde kritik değerler arasında incelenmiştir. \%5 anlamlılık düzeyinde hipotez reddedilmiştir. Buna göre DYY, Enflasyon, İşsizlik ve Sanayi Üretimi arasında uzun dönemde birlikte hareket ettikleri ve 4 değişken arasında eş bütünleşme olduğu sonucuna ulaşılmıştır.

Bir makroekonomik yapının üzerinde herhangi bir değişkenin etkili olup olmadığını inceleyen diğer yöntemlerden biri de etki-tepki fonksiyonlarıdır. Etki-tepki fonksiyonlarının grafikleri ile ilk önce modeldeki değişkenlere verilen şoklara açıkların tepkisi bakımından daha sonra da açıklara verilen şoklara modeldeki değişkenlerin tepkisi bakımından incelenmektedir. .Etki tepki grafiklerine göre tüm değişkenler, her göstergede meydana gelen şokları azaltmak için indirgeyici bir şekilde yanıt vermektedir. Şoklar etkisini ortalama 3 ayda kaybetmiştir.

Seçilmiş değişkenler arasında bir eş bütünleşme ilişkisinin olup olmamasının sorgulanması kadar, bu değişkenlerin birbirlerini etkileme dereceleri de önemlidir. Literatürde bu yönde bulgulara ulaşılmak için VAR modelinden hareketle "varyans ayrıştırması" hesaplamaları kullanılmaktadır. Varyans ayrıştırması ile ilgili yapılan hesaplamalar aşağıdaki tablolarda gösterilmektedir. Varyans ayrıştırması, değişkenlerden birindeki değişimi, tüm değişkenleri etkileyen ayrı ayrı şoklar olarak ayırmaktadır. Varyans ayrıştırmasıyla değişkendeki değişmelerin ne kadarının kendisinden, ne kadarının sistemdeki diğer değişkenlerden kaynaklandığı belirlenmeye çalışımaktadır. 1. dönemde DYY'nin kendisi üzerindeki açıklama gücü \%99,97 iken 10. döneme gelindiğinde \%96,96 seviyelerine düşmektedir. Doğrudan yabancı yatırımlarda zaman içerisinde meydana gelen değişimi açıklama gücü en yüksek değişken enflasyon olarak gözükmektedir. Enflasyonun varyans ayrıştırmasına bakıldığında ilk dönemde sadece kendi üzerinde açıklama gücü vardır. 10. dönem periyoduna gelindiğinde ise \%98'lik kısmı kendisinden kalan \%2'lik kısmın en büyük payı \%0,93 ile sanayi üretiminden açıklanmaktadır. Sanayi üretimi varyans ayrıştırması tablosuna bakıldığında ilk dönemde neredeyse tamamı kendisi tarafından açıklanmakta olup dönem ilerledikçe istikrarlı bir şekilde enflasyon ve işsizlik tarafından açıklanma gücünde artış yaşanmıştır. DYY'nin sanayi üretimi üzerindeki açıklama gücünün çok zayıf olduğu da dikkat çekmektedir. İşsizliğe gelen bir şokun \%98,38 lik kısmı ilk dönem kendinden açıklanırken, 10 dönem sonra \%93,35 lik kısmı kendinden yaklaşık olarak \%6,65 lik kısımları ise DYY, sanayi ve enflasyon üzerinde açıklanmaktadır. İşsizliğin 10 dönemlik periyotta kendi üzerindeki etkisi \%5 lik bir azalma göstermektedir.

\section{SONUÇ}

1930'lu yıllarda yaşanan Büyük Buhran ve sonrasında başlayan İkinci Dünya Savaşı, dünya ekonomisinde büyük hasarlara yol açmış ve çoğu ülkelerin batma noktasına gelmesine, krizlere neden olmuştur. Krizden çıkış yolları arayan ülkeler dünya ticaretinin serbestleşmesi yönünde adımlar atmaya başlamıştır. Gelişmiş ülkeler yeni pazarlara açılmak, ucuz hammadde sağlamak, daha ucuz iş gücüne yönelmek ve ölçek ekonomilerine geçebilmek; gelişmekte olan ülkeler ise büyüme ve kalkınmaları için gerekli olan fonlara erişebilmek amacıyla, sermaye akımlarının serbestleşmesini desteklemişlerdir. 1980'lerle birlikte gelişmiş ülkelerde finansal serbestleşme akımları hız kazanırken Türkiye'de bu akıma uymak zorunda kaldı. Sanayileşme amaçı korumacı ve müdahaleci mekanizmaların ortadan kaldırılması, finansal piyasaların serbestleştirilmesi, dış ticaret üzerindeki kontrollerin gevşetilmesi ve uluslararası sermaye hareketlerinin serbestleştirilmesi ile bu akıma Türkiye'de katılmıştır. Türkiye ekonomisinde doğrudan yabancı sermaye yatırımları ile ekonomik büyüme göstergeleri enflasyon, işsizlik, sanayi üretim endeksi arasında uzun dönemde sıkı ilişki içerisinde olduğu görülmektedir.Yapılan analizlere göre yabancı sermaye yatırımlarının arttıııması için uygun fiziki ortamın yaratılması, ülke içi ekonomik ve siyasi istikrarın sağlanması, teşvik edici düzenlemelerin gerçekleştirilmesi, özellikle ekonomik büyüme göstergeleri olan enflasyon ve işsizlik oranlarını düşürücü, sanayi üretimini arttırıcı politikaların izlenmesi gerekmektedir.

\section{KAYNAKÇA}

Acar, Merve (2016), Doğrudan Yabancı Sermayenin Ekonomik Büyümeye Etkisi: Türkiye Örneği, Kastamonu Üniversitesi IïBF Dergisi, Sayı:13

Ağır, Hüseyin ve Rutbil, Merve (2019), "Türkiye'de Doğrudan Yabancı Yatırımlar ve Ekonomik Büyüme İlişkisi”, Maliye Araştırmaları Dergisi, Cilt: 5, Sayı: 3, s.287-299

Alagöz, Mehmet \& Erdoğan, Savaş \& Topallı, Nurgün (2008), “ Doğrudan Yabancı Sermaye Yatırımları ve Ekonomik Büyüme: Türkiye Deneyimi 1992-2007", Gaziantep Üniversitesi Sosyal Bilimler Dergisi, Cilt: 7, Sayı: 1, s.79-89

Canbay, Ş. (2018), Finansal Serbestleşme Sürecinde Kısa Vadeli Sermaye Hareketlerinin Kontrolü ve Mevcut Risklere Karşı Önlemler, Fırat Üniversitesi Uluslararası İktisadi ve İdari Bilimler Dergisi, 2(1), s.3 
Canbay, Şerif ve Kırca, Mustafa (2020), "Türkiye'de Doğrudan Yabancı Sermaye Yatırımlarının İssizlik Üzerine Etkileri: 1991-2016 Dönemi”, Süleyman Demirel Üniversitesi Vizyoner Dergisi, Cilt: 11, Sayı: 26, s.154-163

Karaçor, Zeynep \& Umutlu, Hasan \& Kasap, Orhan (2017), “ Doğrudan Yabancı Yatırımlar Ekonomik Büyüme İlişkisi”, I. Uluslararası Sosyal ve Ekonomik Araştırmalar Öğrenci Kongresi, s. 219-226

Koyuncu, Fatma Turan (2017), “Doğrudan Yabancı Yatııımlar, Ekonomik Büyüme ve İstihdam Arasındaki ilişki: Türkiye Uygulaması (19902015)", Uluslararası Sosyal ve Ekonomik Bilimler Dergisi, s. 17-24

Mucuk, Mehmet \& Demirsel, Mustafa Tahir (2009), "Türkiye'de Doğrudan Yabancı Yatırımlar ve Ekonomik Performans", Selçuk Üniversitesi Sosyal Bilimler Dergisi, s.365-373

Yılmazer, Mine (2010), "Doğrudan Yabancı Yatırımlar, Dış Ticaret ve Ekonomik Büyüme İlişkisi: Türkiye Üzerine Bir Deneme”, Celal Bayar Üniversitesi Sosyal Bilimler Dergisi, Cilt: 8, Sayı: 1, s.241-260 